\title{
Agarose Gel as a Soil Analogue for Novel Ground Improvement Applications
}

\author{
Javier Rodriguez Corral ${ }^{1}$, Helen Mitrani ${ }^{2}$, Martyn Dade-Robertson ${ }^{1}$, Meng Zhang ${ }^{3}$ \\ ${ }^{1}$ School of Architecture, Planning and Landscape, Newcastle University \\ Newcastle upon Tyne, UK \\ J.Rodriguez-Corral2@newcastle.ac.uk; martyn.dade-robertson@newcastle.ac.uk \\ ${ }^{2}$ School of Engineering, Newcastle University \\ Newcastle upon Tyne, UK \\ helen.mitrani@newcastle.ac.uk \\ ${ }^{3}$ Department of Applied Sciences, Northumbria University \\ Newcastle upon Tyne, UK \\ meng.zhang@unn.ac.uk
}

\section{Extended Abstract}

Biological agents can be used to mitigate construction problems - such as poor-quality soils - in a more sustainable manner. For instance, [1] developed an environmentally-friendly bio-mediated soil reinforcement method which improves the properties of sandy soils using bacteria as the trigger for calcite precipitation.

Furthermore, recently, a new multidisciplinary field has emerged called Synthetic Biology, based on Genetic Engineering of microorganisms, which attempts to engineer biological systems in such a way that their properties and response to external stimulus from their environment can be controlled [2]. For instance, [3] proposes a system in which bacteria cells are engineered to respond to pressure changes and synthesize bio-cement through Microbially-Induced Calcite Precipitation for ground improvement purposes. Further, Synthetic Biology could also have an impact on the development of low-cost and harmless soil bioremediation techniques [4].

However, the implementation of genetically modified organisms (GMOs) on civil infrastructure systems is far from realistic due to the constraints involved when manipulating this type of living organisms outside a controlled environment. Therefore, a method is needed in which GMOs can be cultured in a high controllable material with appropriate mechanical properties and tested under different physical and chemical conditions.

Thus, this abstract introduces the concept of agarose gel as a soil analogue for engineered bacteria testing. An experimental investigation is performed to analyse the mechanical properties of agarose gels and describe their similarities to saturated cohesive soils. Scanning Electron Microscope (SEM) inspection showed that agarose gels have a fibre-pore honeycomb microstructure, with pore sizes ranging $0.2-20 \mu \mathrm{m}$ in diameter, depending on the agarose concentration values somewhat similar to those present in clayey soils. Further, mechanical tests (Unconfined Compression and Unconsolidated Undrained Triaxial) have been performed, indicating $6 \% \mathrm{w} / \mathrm{v}$ concentration gels have a shear strength of 25-30 kPa, which is comparable to soft-firm cohesive soils. Oedometer tests were also performed in order to analyse the one-dimensional consolidation behaviour of the gels. The results suggested that the value of the coefficient of consolidation for $6 \% \mathrm{w} / \mathrm{v}$ agarose gels ranges between $0.8-2 \mathrm{~m}^{2} /$ year, depending on the stress level. Furthermore, the permeability of the gels was also analysed and the values obtained for vertical hydraulic conductivity ranged between $4 \times 10^{-11}$ and $8 \times 10^{-11} \mathrm{~m} / \mathrm{s}$, depending on the effective stress applied. Moreover, consolidation has a considerable effect upon these values due to the high compressibility of the gels.

Therefore, the results show that agarose gels can be a valuable soil analogue and their implementation could contribute to the development of novel bacteria-based ground improvement methods. 


\section{References}

[1] J. T. DeJong, M. B. Fritzges, K. Nusslein, "Microbial Induced Cementation to Control Sand Response to Undrained Shear," J. Geotech. Geoenviron. Eng., vol. 132, no. 11, pp. 1381-1392, 2006.

[2] D. Endy, "Foundations for Engineering Biology," Nature, vol. 438, pp. 449-453, 2005.

[3] M. Dade-Robertson, J. R. Corral, H. Mitrani, M. Zhang, A. Wipat, C. Ramirez-Figueroa, L. Hernan, "Thinking Soils: A synthetic biology approach to material based design computation," in ACADIA 2016 - Posthuman Frontiers: Data, Designers and Cognitive Machines, Ann Arbor, Michigan, 2016.

[4] H. König, D. Frank, R. Heil, C. Coenen, "Synthetic Genomics and Synthetic Biology Applications between Hopes and Concerns," Current Genonims, vol. 14, pp. 11-24, 2013. 